\title{
Microstructural characteristics, porosity and strength development in ceramic-laterized concrete
}

\author{
P.O. Awoyera ${ }^{\mathrm{a}, \mathrm{b}^{*}}$, J. O. Akinmusuru ${ }^{\mathrm{a}}$, A.R. Dawson ${ }^{\mathrm{b}}$, J.M. Ndambuki ${ }^{\mathrm{c}}$, N.H. Thom ${ }^{\mathrm{b}}$ \\ ${ }^{a}$ Department of Civil Engineering, Covenant University, PMB 1023 Ota, Nigeria \\ ${ }^{b}$ Department of Civil Engineering, University of Nottingham, University Park, NG7 2RD \\ Nottingham \\ ${ }^{\mathrm{c}}$ Department of Civil Engineering, Tshwane University of Technology, Pretoria, South Africa
}

\begin{abstract}
Interfacial bonding between constituent materials and pore sizes in a concrete matrix are major contributors to enhancing the strength of concrete. In a bid to examine how this phenomenon affects a laterized concrete, this study explored the relationship between the morphological changes, porosity, phase change, compressive, and split tensile strength development in a ceramic-laterized concrete. Varying proportions of ceramic aggregates, sorted from construction and demolition wastes, and lateritic soil were used as substitutes for natural aggregates. Strength properties of the concrete specimens were evaluated after 7, 14, 28 and 91 days curing, but morphological features, using secondary electron mode, were examined only at 7 and 28 days on cured specimens, using Scanning electron microscope (SEM). From all the mixes, selected samples with higher 28 day crushing strength, and the reference mix, were further characterized with more advanced analysis techniques, using the mercury intrusion porosimetry (MIP), thermogravimetric analysis (TGA), X-ray Diffractometer, and SEM (backscatter electron modefor assessment of the interfacial transition properties between aggregates and paste).

The reference mix yielded higher mechanical properties than the concrete containing secondary aggregates, this was traced to be as a result of higher peaks of hydration minerals of the concrete, coupled with its low tortuosity and compactness. However, a laterized concrete mix containing both $90 \%$ of ceramic fine and $10 \%$ of laterite as fine aggregate provided the optimal strength out of all the modified mixes. Although, the strength reduction was about $9 \%$ when compared with the reference case, however, this reduction in strength is acceptable, and does not compromise the use of these alternative aggregates in structural concrete.
\end{abstract}

Keywords: ceramic waste, microstructure, ITZ, mineralogy, porosity, laterite 


\section{Introduction}

The persistent call for recycling and reuse of construction and demolition wastes currently is driven by the desire to reduce the impact of waste disposal into landfills and at the same time to mitigate depletion of natural resources. Many industrial and construction wastes are toxic and harmful [1,2], and one of these harmful construction wastes is ceramics.

Ceramic products are important components of modern construction being found in sanitary ware and tiling. Increasing urbanization has contributed immensely to the large volume of ceramics produced yearly. Records show that Spain is currently the world market leader in production and exportation of ceramic sanitary ware [3], producing approximately 7 million ceramic ware products annually. Usually during production of ceramic products, wastes are generated which represent about one third of the total volume of materials.

At present, ceramic wastes are mostly not recyclable and, consequently, these materials report to landfill [4]. Its deposition into landfills challenges the environment [5,6] and its handling can incur health and safety issues due to the very sharp edges often occurring on broken faces. However, it is interesting that some experimental studies have indicated that ceramic wastes are adequate as partial replacement for cement and natural aggregates [7-11].

In developing sub-Saharan African countries (and in other places), the wide availability of laterite has helped local communities build their houses using laterite for brick making. Such bricks are usually stabilized using cement or lime so as to increase their strength. However, a few studies [12-14], have suggested the use of laterite as a partial replacement for sand in making laterized concrete. A recent investigation [15], showcased the suitability of crushed ceramic floor and wall tiles as aggregates in laterized concrete. In that study, both the compressive and tensile strengths of concrete made with laterite and ceramic wastes were evaluated. However, the mechanical behaviour of concrete materials mostly depends on its intrinsic microstructure [16], therefore it is vital to also investigate the microstructural morphology of such modified concrete so as to understand how the components affect the concrete strength.

Concrete's strength, particularly its compressive strength, is considered to be its most important property, although other properties relating to deformability and durability cannot be ignored. Various microstructural changes occur when concrete hardens [17-19], mostly as a result of hydration of calcium and aluminate compounds in the presence of water. Consequently, the microstructure of cemented materials is essentially determined by the compounds formed during 
the hydration reactions of the clinker's constituents [20], while, in turn, this microstructure is one of the factors controlling compressive strength [21].

Some studies have evaluated how different factors affect both the microstructure and strength properties of recycled concrete $[3,22,23]$. These have shown that materials such as powdered glass and crushed ceramics from sanitary ware can affect the microstructure of concrete. However, the investigation reported in this paper aims to understand the intrinsic microscale changes in laterized concrete made with ceramics and how this addition affects compressive strength.

\section{Materials and Method}

The materials used in this study for producing the different concrete mixes were granite of 12.7 $\mathrm{mm}$ nominal size, river sand $(\leq 4 \mathrm{~mm}$ sizes), ceramic fine and coarse aggregate processed to similar sizes as the natural aggregates, laterite and Ordinary Portland Cement (OPC). All the constituent materials were prepared in conformity with standards [24-28]. The physical properties of the materials are presented in Table 1, the test values satisfied the standard requirement for aggregates to be used in different types of concrete.

Table 1. Physical properties of the aggregates used

\begin{tabular}{lccccc}
\hline Properties & $\begin{array}{l}\text { River } \\
\text { sand }\end{array}$ & Laterite & Ceramic fine & Ceramic coarse & Granite \\
& 2.61 & 2.13 & 2.26 & 2.31 & 2.87 \\
Specific gravity & 2.24 & 4.70 & 2.52 & 0.55 & 0.23 \\
Water absorption (\%) & 2.24 & 1.80 & 2.20 & 6.88 & 6.95 \\
Fineness modulus & - & - & - & 20.86 & 34.00 \\
Aggregate crushing value & - & - & - & 27.00 & 24.00 \\
Aggregate impact value & - & & & & \\
\hline
\end{tabular}

Figure 1 shows the aggregates used for making the concrete, while their particle size distribution is presented in Figure 2(a). The chemical oxide composition of laterite, cement and ceramics, as obtained from a parallel study [29], is shown in Figure 2 (b). The results of chemical analysis (using X-ray fluorescence (XRF) method) showed that the ceramic tile powder satisfied the condition for pozzolans [30] in that the combination of $\mathrm{SiO}_{2}$ and $\mathrm{Al}_{2} \mathrm{O}_{3}$ (equaling 86.13wt \%) is greater than $70 \mathrm{wt} \%$. The XRD spectrum showing the mineralogy of cement, ceramics and laterite are presented in Figures 3, 4 and 5 respectively. 

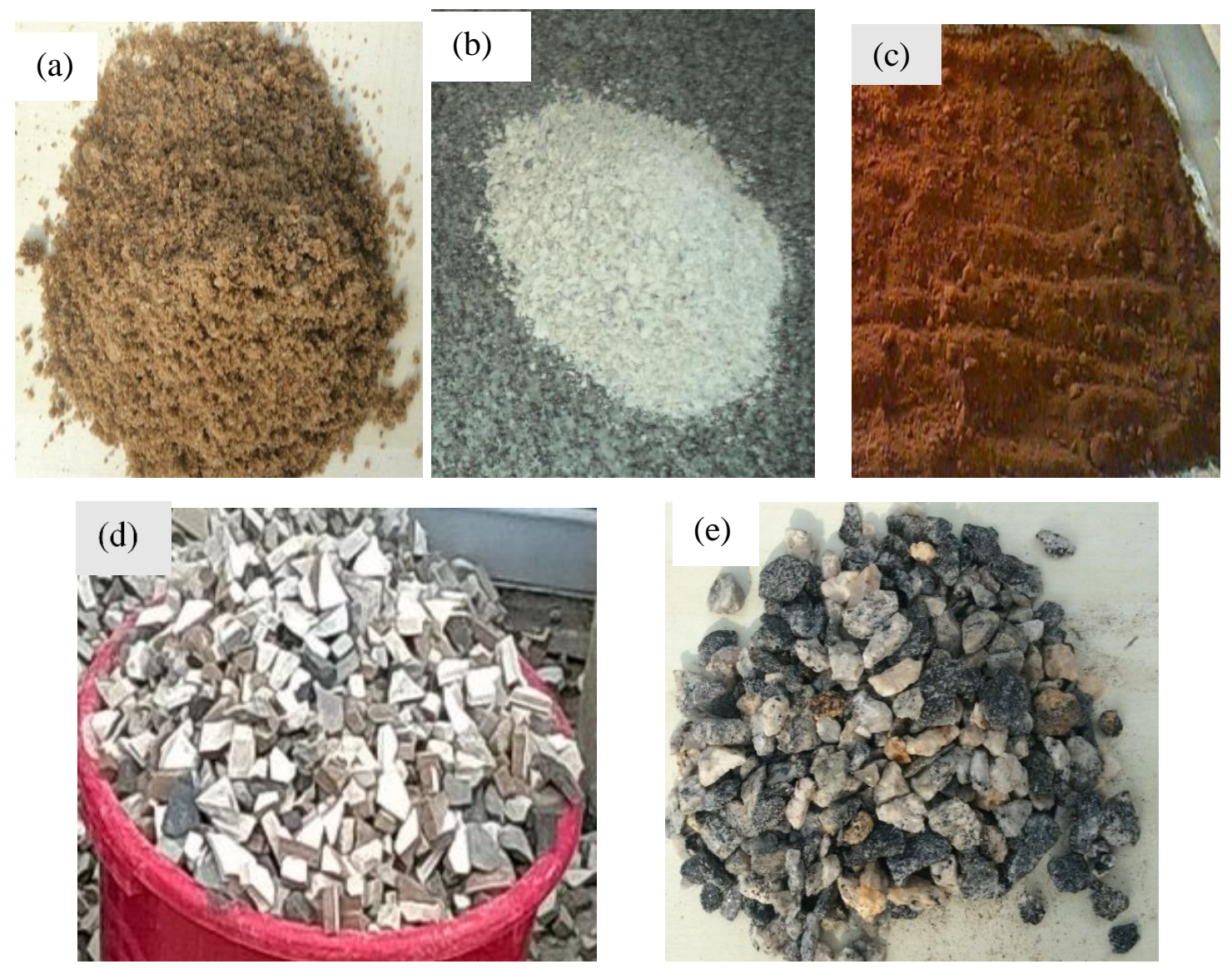

Figure 1. Aggregates used (a) river sand (b) fine ceramics (c) laterite (d) coarse ceramics (e) granite
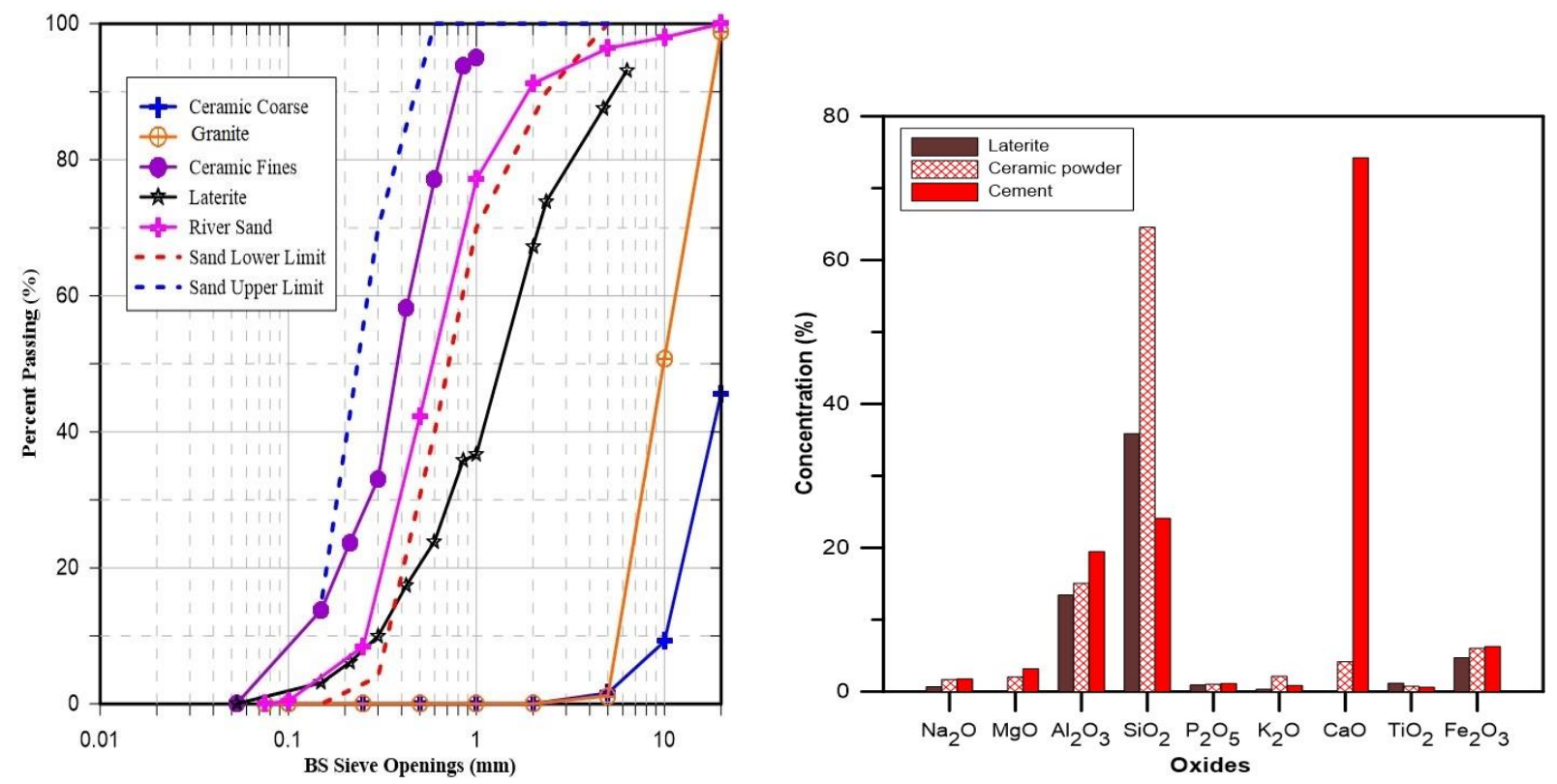

Figure 2. (a) Particle size distribution of aggregates (b) Metallic oxide composition of materials 


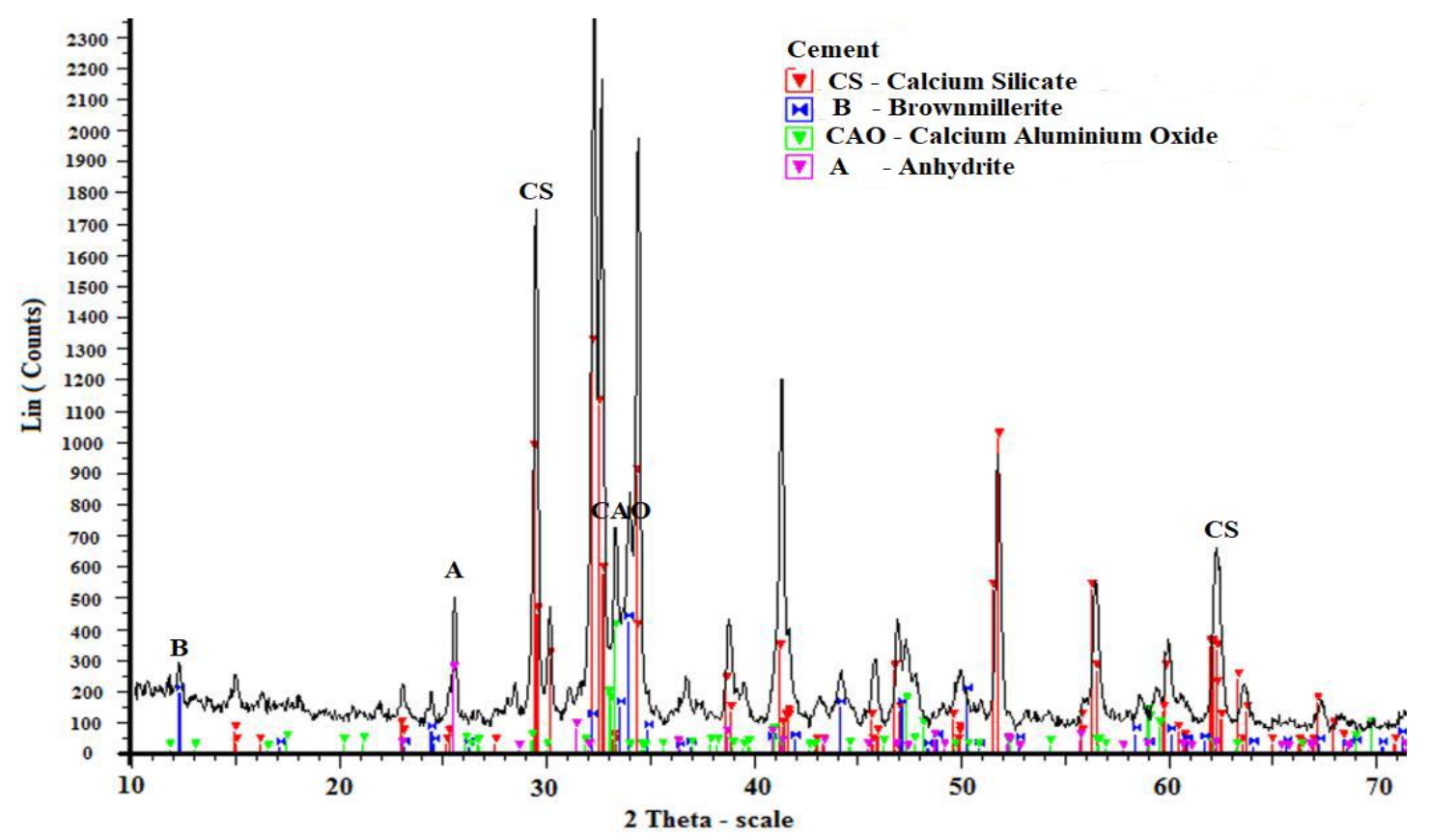

Figure 3. XRD spectra, showing the mineralogy of cement

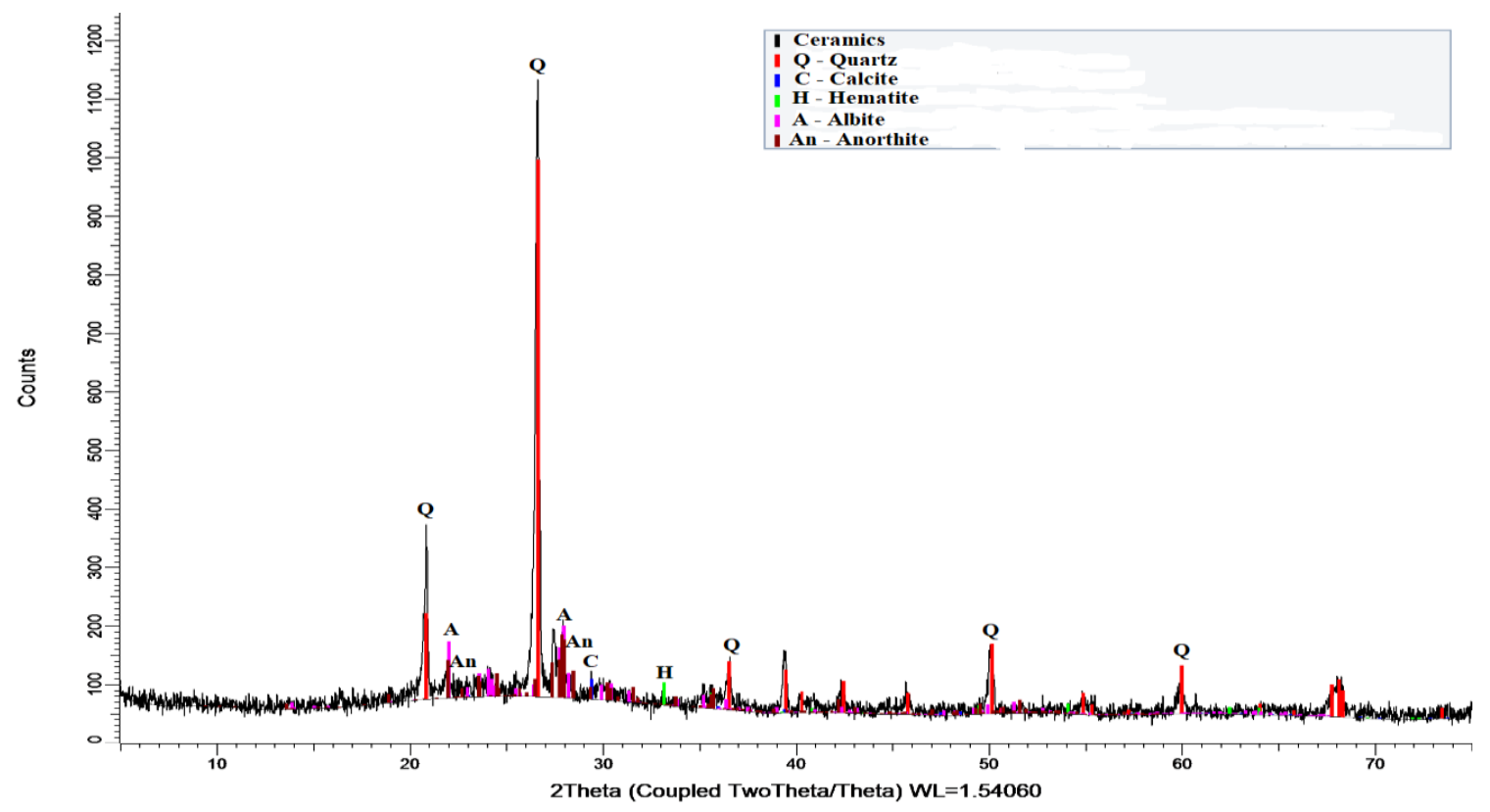

Figure 4. XRD spectra, showing the mineralogy of ceramic powder 


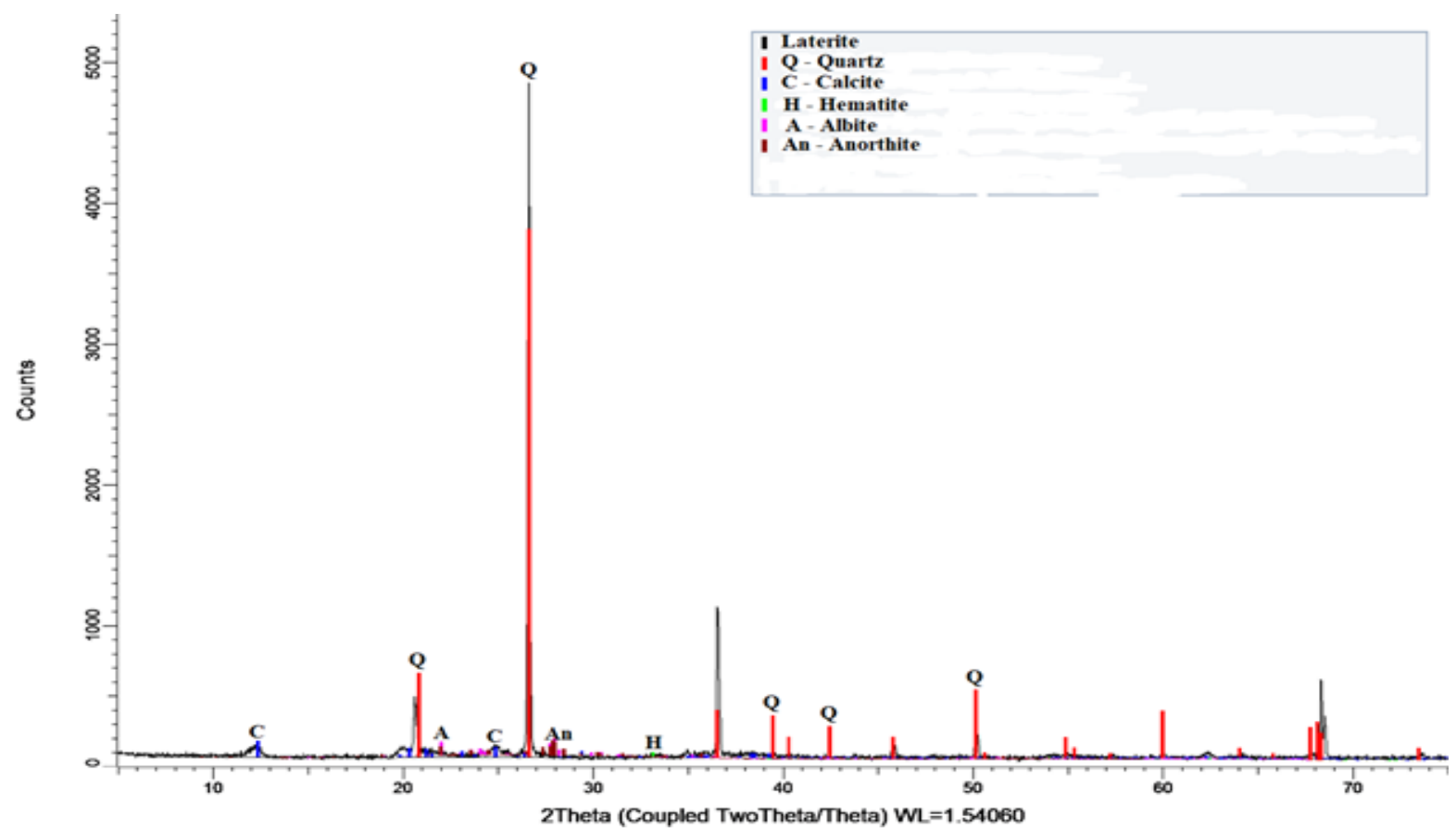

Figure 5. XRD spectra, showing the mineralogy of laterite

Concrete mixing was performed for the selected laterized concrete samples, based on the mix proportion design shown in Table 2.

Table 2. Mix proportion design (\%) for concrete samples

\begin{tabular}{l|l|lll|ll|l}
\hline \multirow{2}{*}{ Mix ID } & Binder & \multicolumn{3}{|c|}{ Fine Aggregates } & \multicolumn{2}{|c|}{ Coarse Aggregates } & w/c \\
\cline { 2 - 6 } & Cement & Sand & $\begin{array}{l}\text { Ceramic } \\
\text { fine }\end{array}$ & Laterite & Granite $\begin{array}{l}\text { Ceramic } \\
\text { coarse }\end{array}$ & \\
\hline M0 & 100 & 100 & - & - & 100 & - & 0.6 \\
M10 & 100 & 90 & - & 10 & 100 & - & 0.6 \\
M20 & 100 & 80 & - & 20 & 100 & - & 0.6 \\
N0 & 100 & - & 100 & - & 100 & - & 0.6 \\
N10 & 100 & - & 90 & 10 & 100 & - & 0.6 \\
N20 & 100 & - & 80 & 20 & 100 & - & 0.6 \\
N30 & 100 & - & 70 & 30 & 100 & - & 0.6 \\
L0 & 100 & - & 100 & - & & 100 & 0.6 \\
L10 & 100 & - & 90 & 10 & & 100 & 0.6 \\
L20 & 100 & - & 80 & 20 & & 100 & 0.6 \\
L30 & 100 & - & 70 & 30 & & 100 & 0.6 \\
\hline
\end{tabular}

A characteristic compressive strength of $25 \mathrm{MPa}$ was targeted, with a constant water-binder ratio of 0.6. The slump of the fresh concrete mixes was tested to evaluate its workability. For all the mixes, $150 \mathrm{~mm}$ dimension concrete cubes, and cylinders of $100 \mathrm{~mm}$ diameter and $200 \mathrm{~mm}$ depth 
were prepared in triplicate and cured in water for a maximum of ninety one (91) days at a temperature of $20 \pm 1^{0} \mathrm{C}$. In order to achieve the desired consistency or workability in mixes with a large quantity of ceramics, 0.6 water-binder ratio was used, primarily so as to complement the water absorption (coefficient of $0.55 \%$ ) of ceramic tile aggregate being more than four times as much that of the granite $(0.13 \%)$.

The concrete cubes and cylinders were subjected to compressive and split tensile testing at 7, 14, 28 and 91 days curing periods, according to [31,32], using a $2000 \mathrm{kN}$ compression machine. After crushing of the cubes, broken samples were machined into cubes of approximately $3 \mathrm{~cm}$ dimensions, for microstructural tests from the surface of the specimens. Scanning electron microscope (SEM) images and energy dispersion spectroscopy (EDS) results at 7 and 28 days of the selected mixes were obtained (in secondary electron mode) so as to identify the changes in the morphology of the samples with the intention of relating these changes to associated strength developments.

Scanning electron microscopy (SEM - Hitachi S4100 equipped with energy dispersion spectroscopy, EDS - Rontec) was used, at $5 \mathrm{kV}$ and $25 \mathrm{kV}$, to investigate the microstructure of the samples. Test samples were coated with gold using 10-20 mA DC current, and afterward attached to double-sided carbon tape mounted on a brass stub.

In addition, advanced analysis techniques, mercury intrusion porosimetry, thermogravimetric analysis (TGA), X-ray diffractometer (XRD), and SEM (backscatter electron mode), were used to characterize a selected sample (having higher compressive and split-tensile strengths), alongside reference mix sample. Mortar cubes of $70 \mathrm{~mm}$ dimensions that had been cured in water for 28 days were used for the tests.

Fragments of mortar, obtained from the crushed concrete cubes, were used for the XRD and the TGA tests. The mortar specimen was dried completely in the oven, and afterwards ground with mortal and pestle, and later sieved through a $63 \mu \mathrm{m}$ aperture size. The resulting powder sample was used for both XRD and TGA analysis. The XRD analysis reveals the specimen mineralogical phases, while the TGA test was used to determine the amount of calcium hydroxide $\left(\mathrm{Ca}(\mathrm{OH})_{2}\right)$ derived, as a result of the dehydroxylation of the specimen. A Bruker AXS D8 Advance equipment, having a scanning speed of $2^{\circ}$ per minute was used for the XRD analysis. The scanning process was performed in steps of $0.05^{\circ}$ and at a range 10 to $70^{\circ}$. The TGA was performed using a Q600 TGA-Differential scanning calorimeter. A ramp heating 
procedure was adopted in a nitrogen atmosphere, which allows for a sample to be heated uninterruptedly at different specified rates per minute. In this study, the specimens were heated, initially at $30^{\circ} \mathrm{C}$ per minute up to $300^{\circ} \mathrm{C}$, and subsequently at $20^{\circ} \mathrm{C}$ per minute up to $600^{\circ} \mathrm{C}$. Finally, the weight loss-temperature combined with derivative weight loss-time data obtained were analysed.

For the MIP analysis, a prism sample of $10 \mathrm{~mm}$ x $10 \mathrm{~mm}$ x $20 \mathrm{~mm}$, weighing between 1-2 g, was cut from the middle of the mortar specimen, and subsequently dried at $100^{\circ} \mathrm{C}$ in the oven for 24 hrs. The prisms were carefully sawn from the mortar, in order to avoid distortion, and also, so as to protect the original pore structure of the sample. Thus, drying the specimens after removal from water helps to stop any possible hydration in the samples prior to testing. The MIP test was performed using a Micrometrics Autopore IV mercury porosimeter, having the capacity to detect pores down to $7 \mathrm{~nm}$ diameter, and with a maximum pressure of $212 \mathrm{MPa}$. The analysis was performed using a mercury to solid contact angle of $130^{\circ}$ and mercury surface tension of 485 $\mathrm{mM} / \mathrm{m}$. The MIP was able to capture capillary pores ranging between $0.007 \mu \mathrm{m}$ and $100 \mu \mathrm{m}$. Finally, an attempt was made to measure the features of the ITZ between aggregates and paste of the selected mixes, using SEM analysis in backscatter electron mode. This analysis is essential because the ITZ, among other features, can have a significant effect on strength development in concrete. The sample preparation for this analysis was performed in line with the procedures of Kjellsen et al. [33].

\section{Results and Discussion}

The performance of the concrete mixes in both fresh and hardened states has been evaluated through slump and mechanical tests respectively. The slump results of fresh concrete were in the range 50-60 mm. The reference $\mathrm{M} 0$, and the ceramic but non-laterized mixes, N0 and L0, were found to be more workable than the laterized samples. The low workability of the laterized samples is apparently caused by the presence of kaolinite and illite minerals in the laterite [34], which require additional water to aid plasticity.

\subsection{Compressive Strength}

Prior to testing, the concrete samples were removed from water for approximately $24 \mathrm{~h}$ and were air-dried in the laboratory. Figures $6 \mathrm{a}, 6 \mathrm{~b}$ and $6 \mathrm{c}$ present the compressive strength development 
with curing age, for samples containing cement/ sand /granite, cement/ fine ceramics/ granite, and cement/ fine ceramics/ coarse ceramics, respectively. While Figure $6 \mathrm{~d}$ shows effect of increasing laterite content on the compressive strength of selected mixes. The mechanical tests results reported are the averages of triplicate specimens.

The axial compressive strength of all the concrete samples tested increased as the curing age increased, as with conventional concrete. The compressive strength profile for the reference mix given for comparative purposes in Figure 6 is derived from testing performed by the authors and extended to 91 days on the basis of data obtained from a similar study [13]. It shows only a slight increase in strength beyond 28 days which suggests that the hydration within the concrete matrix reached its peak within 28-days curing. When the 28-days strength is considered, the reference concrete (M0) proved to have better compressive strength than the mixes containing secondary aggregates.

Of the modified mixes, N10 and L10 (containing 10\% laterite) yielded the maximum compressive strength which represented an approximately $11 \%$ strength gain over the modified mixes without laterite, but the compressive strength decreased as the laterite content increased beyond $10 \%$. The categories containing laterite and fine ceramics as fine aggregates have higher strength than the mix containing laterite and sand as fine aggregates. The increased compressive strength in concrete containing minimal laterite $(10 \%)$ could be attributed to the pozzolanic influence of ceramic aggregate, as this contains significant amounts of silica and aluminate [35], which apparently contribute to a prolonged hydration period by causing a reduction in the hydration temperature in the concrete and, this enhanced the compressive strength. This moreover, suggests that an improved interfacial transition zone (ITZ) exist between ceramic aggregate, laterite and hardened cement paste. Though the 28-day strength is recommended for the design of concrete, however, this study revealed that compressive strength of the laterized samples increased slightly beyond 28 days up to 91 days curing periods. A similar result was also reported by Abdelaty [36] from a study on conventional concrete and such long-term strength increases are commonly observed in pozzolanic mixes [37]. All the mixes containing ceramic and/or laterite show lower strengths than the reference, conventional concrete, but the reduction is small for mix L10, even though all the coarse and fine aggregate (other than the $10 \%$ laterite) is ceramic. 

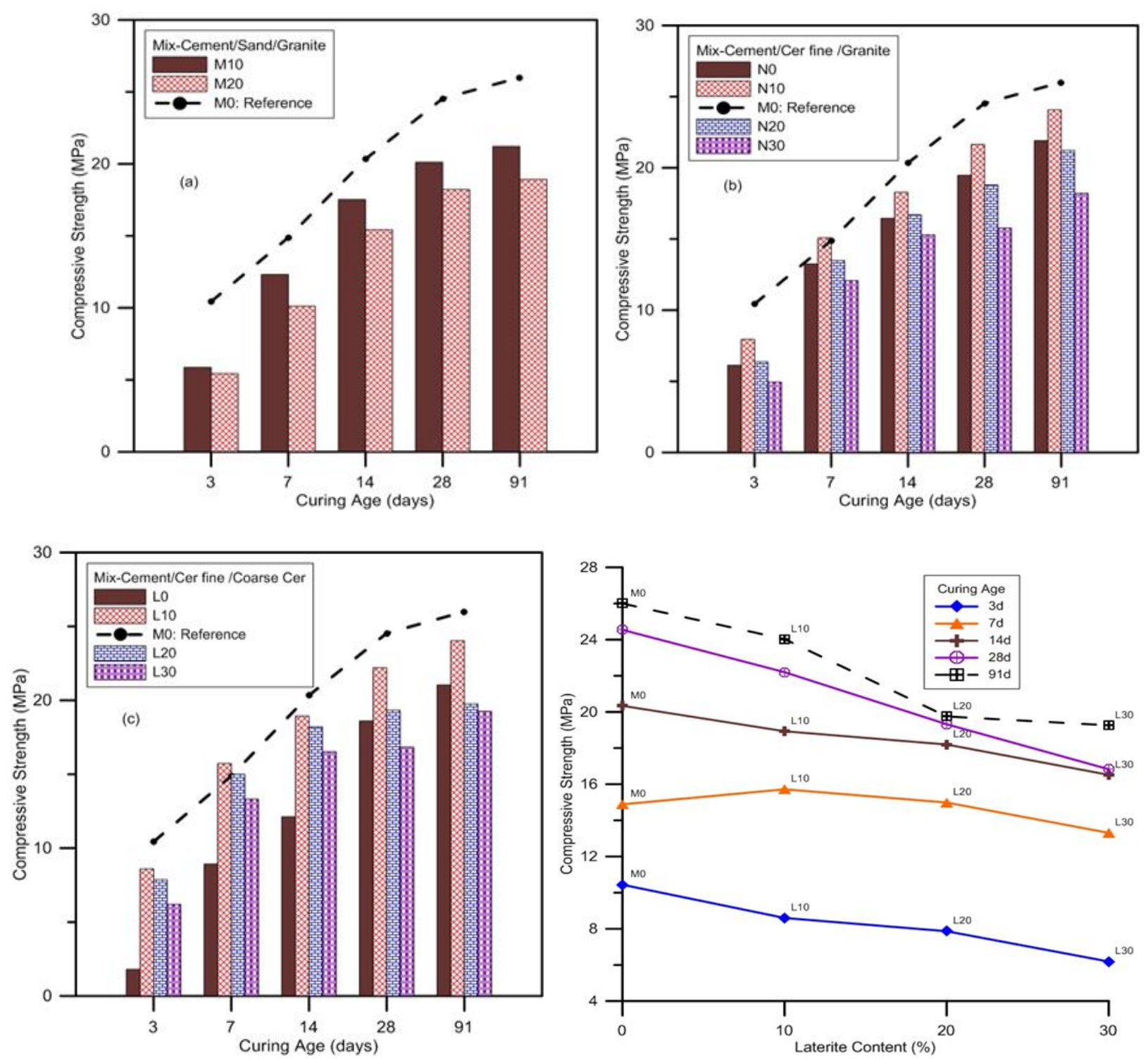

Figure 6. Compressive strength development (a) mix-cement: sand: granite (b) mix-cement: fine ceramics: granite (c) mix-cement: fine ceramics: coarse ceramics (d) with laterite content

\subsection{Split Tensile Strength}

Split-tensile strength of concrete is an indication of the shear resistance provided by concrete materials [38]. The splitting tensile strength of the concrete samples was assessed using the standard method [32]. Figures 7a, 7b and 7c show the split-tensile strength developed by the concrete mixes (cement, sand and granite), (cement, fine ceramics and granite), and (cement, fine ceramics and coarse ceramics) respectively. Once again, the extending of the reference mix data to 91 days uses the results of Balogun and Adepegba [13]. 
Just as observed in the compressive strength tests, split-tensile strength also increased with the curing age of the concrete. In a similar manner, mixes M10, N10 and L10 (containing 10\% laterite) yielded the higher values of split-tensile strength, an approximate $7.6 \%$ strength gain compared with the samples without laterite. Similarly to compressive strength, split-tensile strength also decreased as the laterite content was increased beyond $10 \%$.

This increase in the split-tensile strength of the mixes N10 and L10 may be a result of the considerably higher water content used [39], because there will be enough water for hydration despite absorptions by ceramic aggregate and laterite aggregates before the hydration.
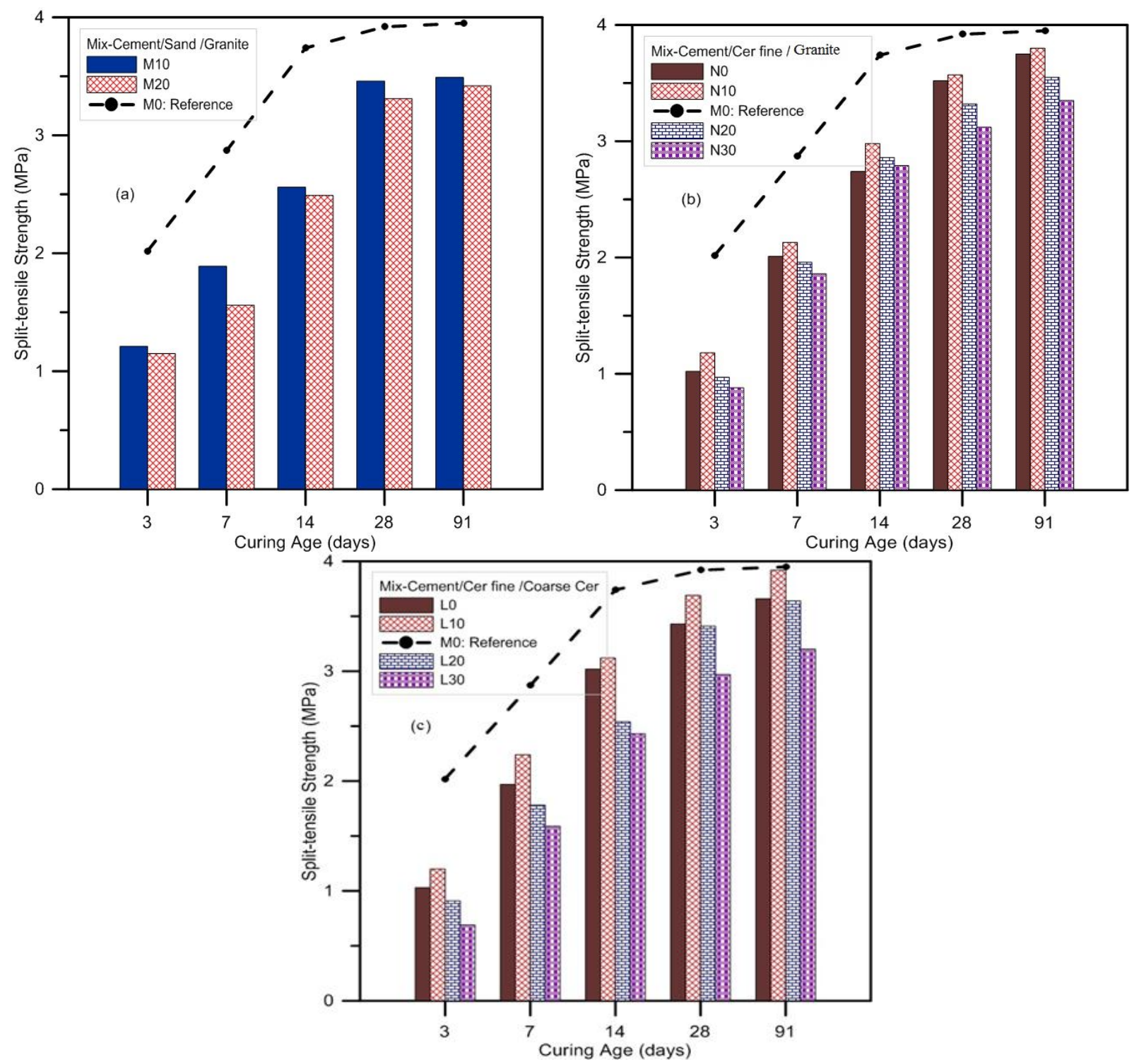

Figure 7. Split-tensile strength development with curing age (a) mix-cement: sand: granite (b) mix-cement: fine ceramics: granite (c) mix-cement: fine ceramics: coarse ceramics 


\subsection{Microstructural Analysis}

Two mixes, comprising the reference and L10 samples, were selected for further evaluation based on their higher strength gain than other samples at 28 days.

The morphology of the selected mixes were obtained through SEM analysis in the secondary electron mode. Figures 8(a) and (b) show the morphology of the reference concrete obtained after 7 and 28 days curing respectively, while Figures 8 (c) and (d) show the morphology of the L10 sample obtained after 7 and 28 days curing, respectively. In the reference concrete, a well refined and hydrated structure was observed, though the 28 day micrograph indicated some micro pores (black spots), but this obviously had no major effect on its strength performance. This mix showed a more compact and refined structure, owing to rapid hydration and this helps to explain their appreciable strength gains.

On the other hand, the morphology of L10 concrete at an age of 28 days (Figure 8d) revealed a surface which appeared ruptured, and largely dominated with disjointed particles, this was as a result of slow hydration of the laterized mix. The morphological appearance in Figure 8d further suggests that there were more un-hydrated particles in the laterized concrete. In this mix, micro pores and cracks are more visible and wide. However, out of all the modified concrete mixtures, L10 demonstrated a substantial 28 day strength that is close to that of the reference mix. This can be explained based on the fact that laterite contains about $45 \%$ silica [15], which can thereby, trigger a pozzolanic reaction between laterite, ceramic and cement, which would in turn contribute to an improvement in strength. Therefore it appears that optimal behaviour is obtained when there is enough laterite for a pozzolanic effect to be gained, but insufficient to deleteriously affect the mix structure. This appears to be the case when there is $10 \%$ laterite content laterized concrete containing ceramic aggregates. The decrease of strength at higher laterite content appears not to be because of less cementation action, but because of pores compactness (packing) or induced shrinkage cracks (see Figure 8e) as reported by Oyelami and Van Rooy [34]. 

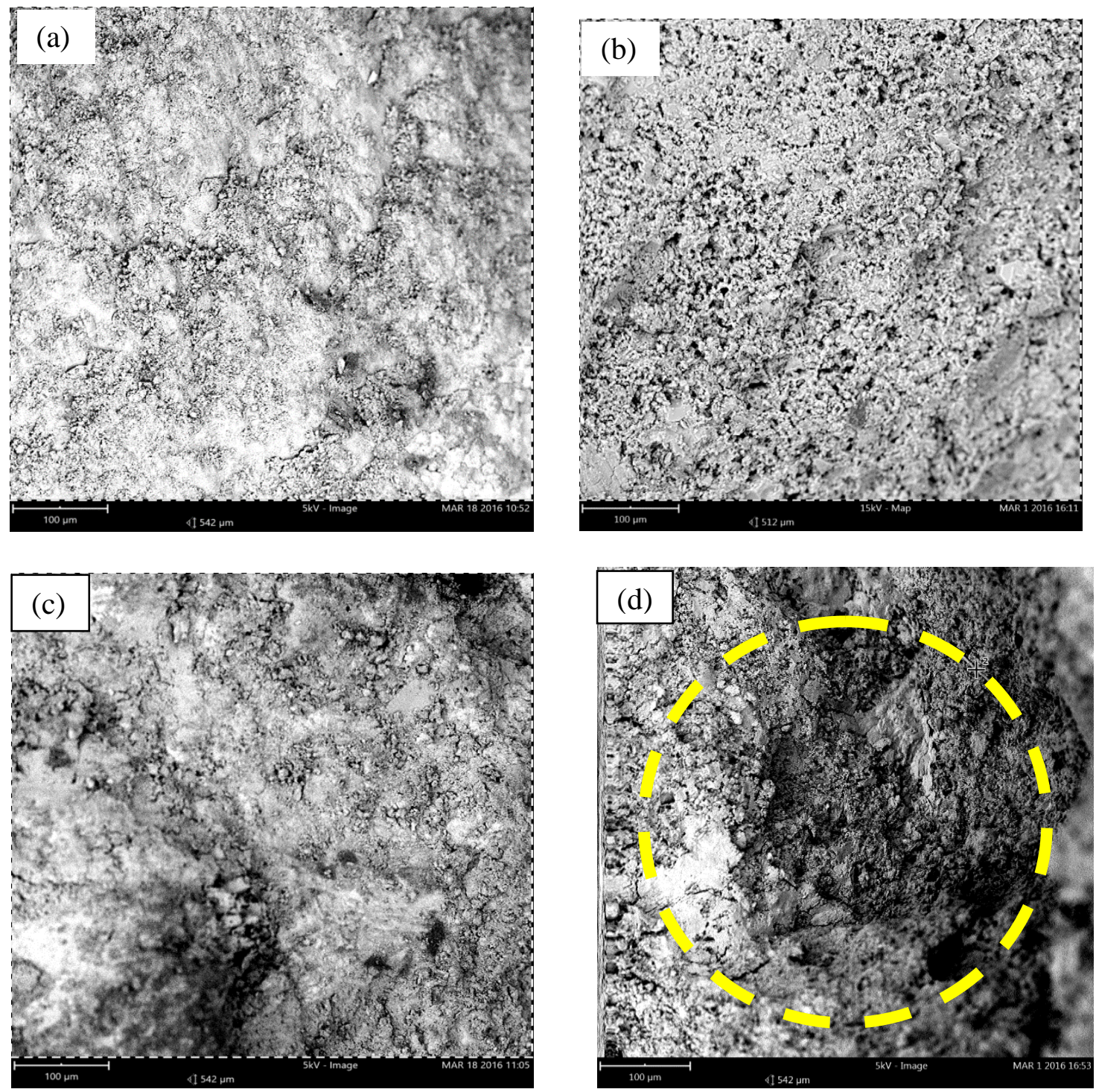

Figure 8. Morphology of (a) reference concrete at 7 days (b) reference concrete at 28 days (c) Mix L10 at 7 days and (d) Mix L10 at 28 days 


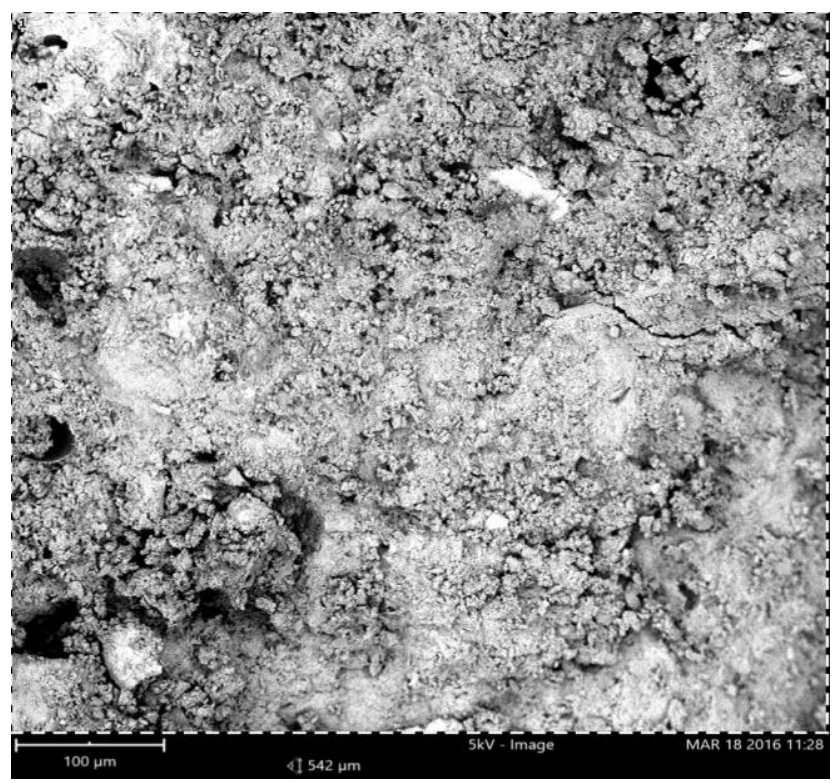

Figure 8 (e). Morphology of a sample having 30\% laterite

\subsubsection{Features of the ITZ using back scattered SEM analysis}

The distribution of the element atomic mass at the ITZ of the selected samples was determined using SEM in the back scattered electron mode. An X-ray line spectrum linked with EDX was used with the SEM. The sample was coated with a thin layer of carbon to make its surface transparent and conductive to electrons. However, another benefit of carbon coating is that carbon peaks in the EDS data can easily be differentiated from the sample elements, without any overlapping of peaks.

The micrograph and element composition, measured across the interphase between the aggregate, ITZ and the bulk cement pastes, for the reference and the L10 mix are shown in Figures 9a and 9b respectively. The EDS analysis was obtained at concentrations normalized to $100 \%$ with a standard deviation of $0.3 \%$ on concentration due to peak profile fitting. The analyses were conducted using an accelerating voltage of $20 \mathrm{kV}$ for each $2 \mu \mathrm{m}$ using a magnification of $3000 \mathrm{x}$. The main composition of calcium silicate hydrate $(\mathrm{C}-\mathrm{S}-\mathrm{H})$, Portlandite $(\mathrm{CH})$ and Ettringite (AFm) phases, occurring in the ITZ region, were determined following the criteria reported by Rossignolo [40], as follows:

$\mathrm{C}-\mathrm{S}-\mathrm{H}$ exist when $0.8 \leq \mathrm{Ca} / \mathrm{Si} \leq 2.5$, and $(\mathrm{Fe}+\mathrm{Al}) / \mathrm{Ca} \leq 0.2$

$\mathrm{CH}$ exist when $\mathrm{Ca} / \mathrm{Si} \geq 10,(\mathrm{Al}+\mathrm{Fe}) / \mathrm{Ca} \leq 0.04$ and $\mathrm{S} / \mathrm{Ca} \leq 0.04$

AFm exist when $\mathrm{Ca} / \mathrm{Si} \geq 4.0,(\mathrm{Al}+\mathrm{Fe}) / \mathrm{Ca}>0.4$ and $\mathrm{S} / \mathrm{Ca}>0.15$ 

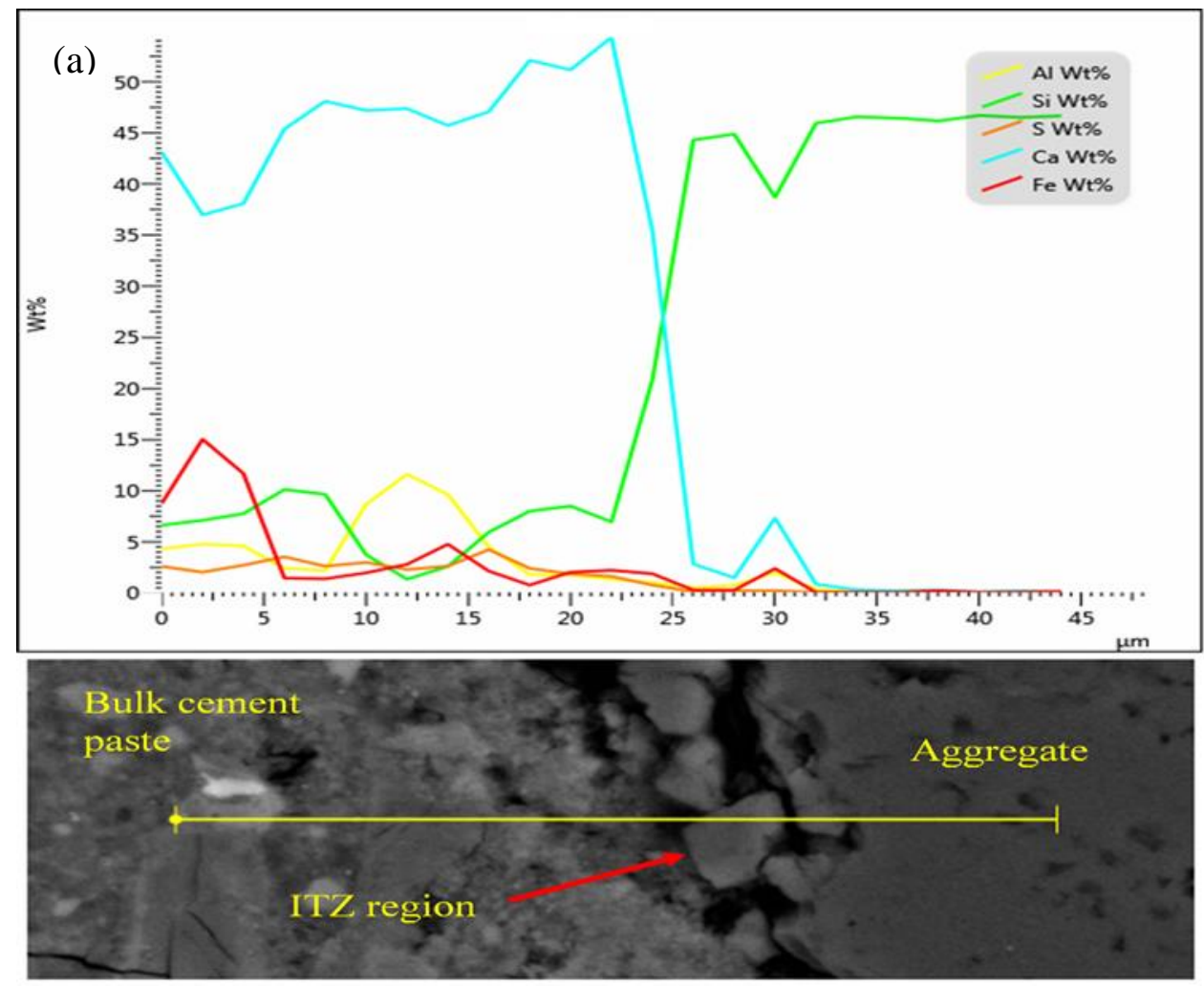

Figure 9a SEM micrograph and element mass distribution at the ITZ in the reference mix

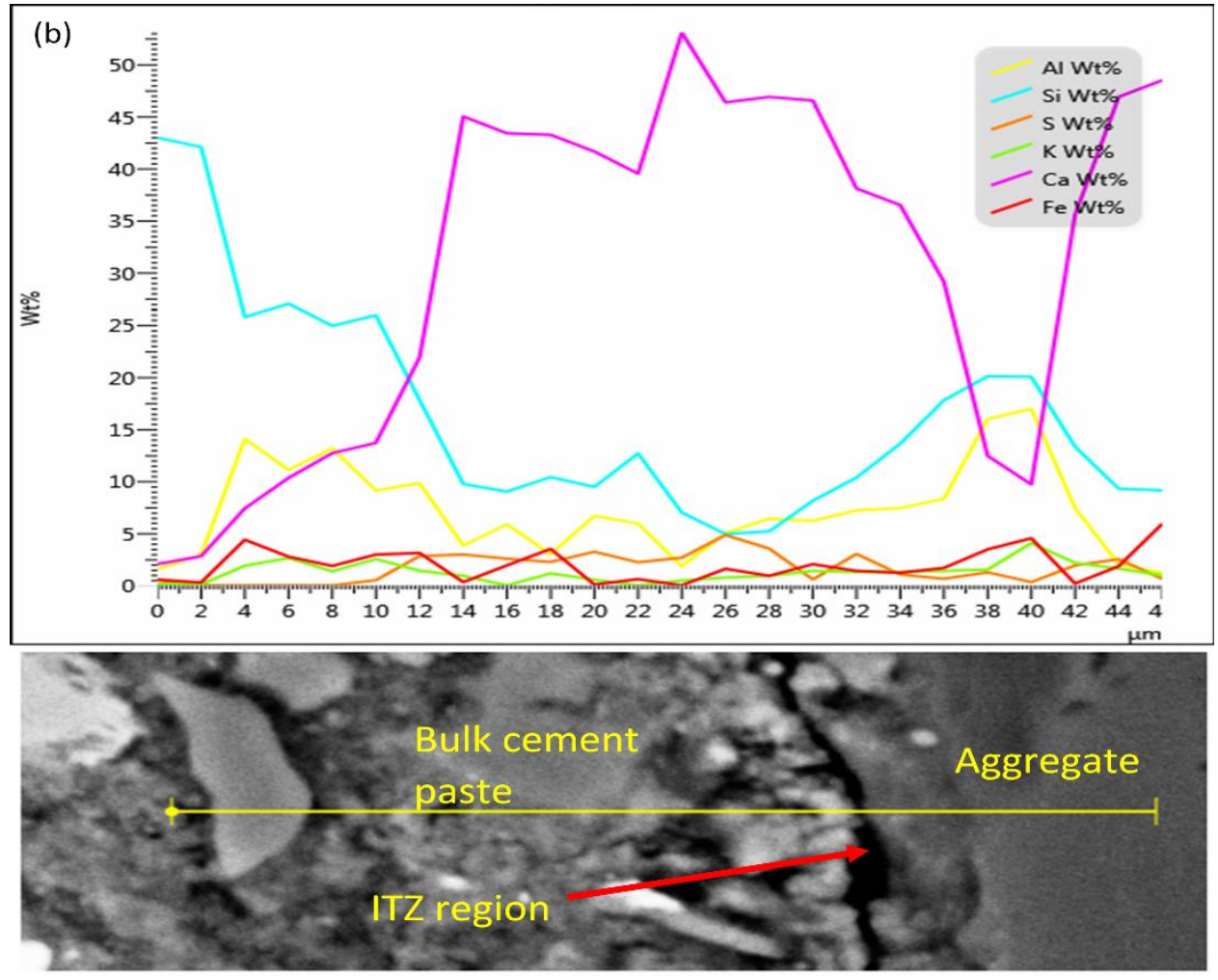

Figure 9b. SEM micrograph and element mass distribution at the ITZ in the mix L10 
The atomic mass ratio for the two samples is shown in Table 3. The data values shown in the table were calculated using the concentration of the elements as obtained from the EDS analysis during SEM evaluation in the backscattered electron mode. In other words, atomic mass ratio is the ratio of the concentrations of the selected elements in the ITZ. The analyses criteria covers only the compositions of major cement hydrated products; $\mathrm{C}-\mathrm{S}-\mathrm{H}, \mathrm{CH}, \mathrm{AFm}$ and Aft, which can also be used to determine the thickness of the ITZ.

Table 3. Atomic mass ratio $\mathrm{Ca} / \mathrm{Si}, \mathrm{Al}+\mathrm{Fe} / \mathrm{Ca}$ and $\mathrm{S} / \mathrm{Ca}$ in the $\mathrm{ITZ}$ of selected mixes

\begin{tabular}{cccc}
\hline Sample & $\frac{C a}{S i}$ & $\frac{A l+F e}{C a}$ & $\frac{S}{C a}$ \\
\hline Reference & 4.14 & 0.06 & 0.02 \\
L10 & 3.68 & 0.23 & 0.08 \\
\hline
\end{tabular}

The EDS analysis revealed Calcium $(\mathrm{Ca})$ as the dominant element in all the mixes, at all ages. Other elements identified include Si, Al, S, K, and Fe. These elements are characteristic of C-S$\mathrm{H}, \mathrm{C}-\mathrm{A}-\mathrm{H}$ and either of ettringite (Aft) or Afm (calcium mono sulfoaluminate hydrated) hydration products, as identified by Rossignolo [40] as listed above.

Therefore, based on the Rossignolo's criteria used for measuring the dominant hydrous phases in the ITZ and cement paste, it can be inferred from the atomic mass ratios that the C-S-H, CH and AFm phases were not that strong in the L10 mix, because all the conditions were not fulfilled. The ITZ characteristics of the selected laterized concrete are somewhat close to that of the reference mix, based on the concentration of the atomic of mass of elements occurring in the ITZ.

However, because the $\mathrm{S} / \mathrm{Ca}$ and $\mathrm{Ca} / \mathrm{Si}$ in the reference sample satisfied Rossignolo's criteria, it was evident that the ITZ zone in the reference concrete has a notable amount of $\mathrm{CH}$ and ettringite.

This interpretation is supported by the findings of Cheng et al. [41]. 


\subsection{XRD mineralogy analysis}

The XRD spectra, showing the mineralogy of the reference mix and the mix L10 mortar powders are shown in Figures 10a and 10b respectively. These were taken from specimens at 28 days after mixing. The dominant crystal phases that were identified from both include: Quartz (Q), Calcite (C), Portlandite (P), Ettringite (E), and Calcium silicate (CS). However, emphasis was based on the more visible mineral peaks such as Ettringite, Calcite and Portlandite, which all originate during the process of hydration in the concrete.

The higher 'noise' in the L10 results relative to the reference results, and the rise of the baseline between 2 Theta $=15^{\circ}$ and 2 Theta $=35^{\circ}$. Both of these are indicative of extensive amorphous phases of minerals in the mixture and may be confidently attributed to the replacement of crystalline quartz in sand fines to amorphous ceramic dust in the L10 mixture. The large drop of the XRD trace in Figure $7 \mathrm{a}$ to that in Figure $7 \mathrm{~b}$ at 2 Theta $=26.5^{\circ}$ will also be due to the replacement of quartzitic sand with amorphous ceramic material. Similar observations were made by Mohammed et al. [42] when performing a mineralogical analysis of self-compacting concretes made using limestone powder and fly ash in place of conventional fillers.

The peaks of Ettringite, Calcite and Portlandite were somewhat higher in the reference mix than in the L10 sample. Portlandite $\left(\mathrm{Ca}(\mathrm{OH})_{2}\right.$ or $\left.\mathrm{CH}\right)$ forms during hydration in cement-based materials and can be responsible for early strength gain in the mix, mainly due to fast selfhydration of the cement [43]. Because the cement added is the same in both cases, the reduction in the $\mathrm{CH}$ peaks after 28 days must be attributed to some of these materials, notably the Portlandite, being partially consumed by the pozzolanic reactions taking place, after the initial cement reactions, in the presence of the added laterite. 

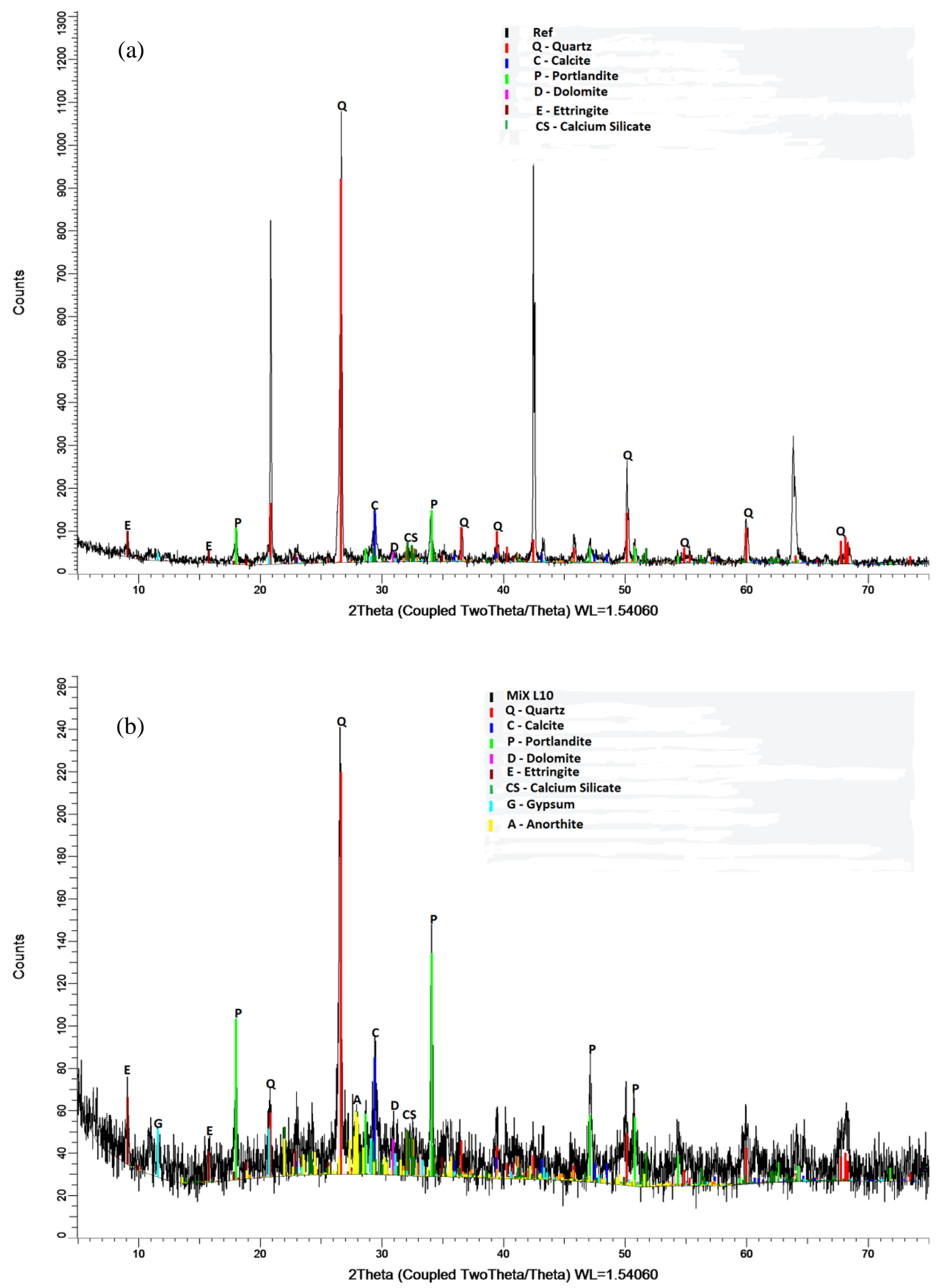

Figure 10. XRD spectra (a) reference concrete (b) mix L10 


\subsection{Hydration Phenomenon}

The weight loss-temperature change data obtained from the thermogravimetric software was analyzed using TA universal analysis 2000 software.

The TGA analysis data, showing the cumulative weight loss of the specimens with respect to increase in temperature, for the reference concrete and mix L10 (containing cement: fine ceramic + laterite: coarse ceramics) are presented in Figures 11a and 11b respectively. Two visible peaks can be seen on this graphs, with the first and second peaks, occurring at about $100^{\circ} \mathrm{C}$ and 420 to $550^{\circ} \mathrm{C}$ respectively. The first peak indicates the dehydration of pore water [44], and the second peak is the dehydroxylation of $\mathrm{CH}$ [45]. When heating process is done below $300^{\circ} \mathrm{C}$, it will showcase the dehydration of pore water in the sample, while subsequent heating (above $300^{\circ} \mathrm{C}$ ) aids the measurement of $\mathrm{Ca}(\mathrm{OH})_{2}$ dehydroxylation [42]. However, the process involving decarbonation in a cement based material, will be measured at a temperature between $600-$ $950^{\circ} \mathrm{C}$. Previous authors $[22,42]$ who used TGA showed that concrete with lower strength is associated with higher amount of $\mathrm{Ca}(\mathrm{OH})_{2}$ during dehydroxylation. Normally, a concrete will have lost above $70 \%$ of its strength when subjected to a temperature around $600^{\circ} \mathrm{C}$ [46], but for lower strength concretes which are depending on the $\mathrm{Ca}(\mathrm{OH})_{2}$ binding action, they can be expected to lose a greater proportion of their strength under the same temperature exposure.

However, this discussion is focused on the dehydroxylation of $\mathrm{CH}$, because it helps to explain the hydration process, and possibly the strength variation in the samples.

For the reference concrete and L10 used for TGA analysis, the peak corresponding to the dehydroxylation occurred at $431.72^{\circ} \mathrm{C}$ and $438.18^{\circ} \mathrm{C}$ respectively (Figures 11a and 11b), and their corresponding weight losses were $1.472 \% / \mathrm{min}$ and $1.286 \% / \mathrm{min}$.

The total amount of $\mathrm{Ca}(\mathrm{OH})_{2}$ or $\mathrm{CH}$ in the powder samples was determined using Equation 1 [47]:

$\% \mathrm{Ca}(\mathrm{OH})_{2}=\% \mathrm{CH}$ de-hydroxylation $=\frac{74}{18 \mathrm{~A}} \quad$ Equation 1

where $\mathrm{A}=$ area under the derivative weight loss curve that corresponds to the total mass lost due to the de-hydroxylation of $\mathrm{CH}$ at a temperature between 420 and $550^{\circ} \mathrm{C}$.

Therefore, using Equation 1, the percent $\mathrm{CH}$ dehydroxylation for the reference concrete and $\mathrm{L} 10$ sample were computed as $2.79 \%$ and $3.20 \%$ respectively. With this result, it can be inferred that the most rapid hydration occurred in the reference concrete, containing conventional aggregates, also, it could be suggested that there was rapid development of CSH gels and this consequently, 
aid the higher strength development in the reference mixture. These results agree with the XRD crystalline phases, in that, the variation in $\% \mathrm{CH}$ was a good match with the identified $\mathrm{XRD}$ peaks.
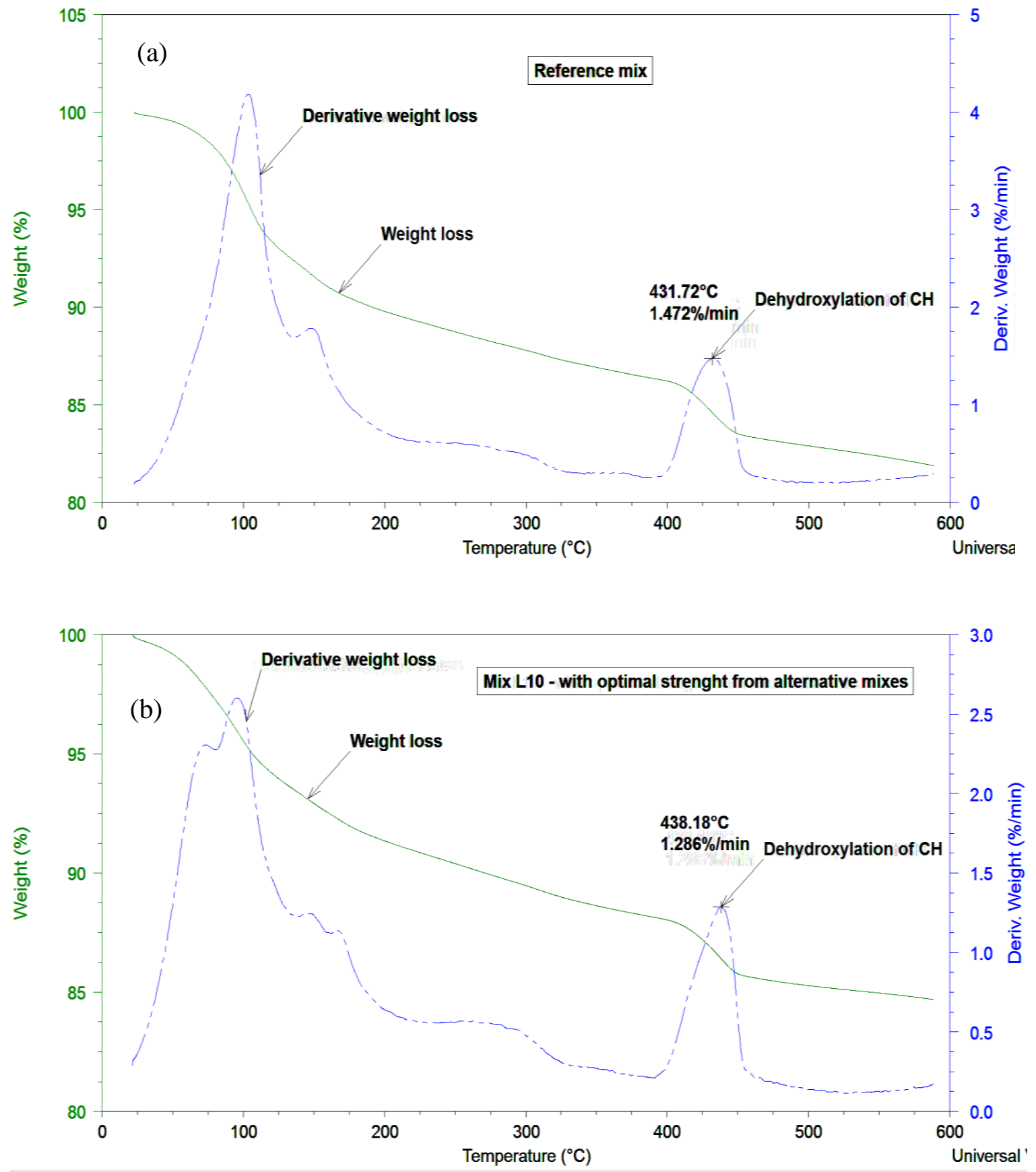

Figure 11. Phase change (a) reference concrete (b) mix L10 


\subsection{Mercury intrusion porosimetry (MIP)}

The MIP results, showing pore parameter for the reference concrete and L10 mix are shown in Figures 12 (a) as the cumulative pore intrusion versus pore size diameter and in (b) as the derivative of the MIP curves.
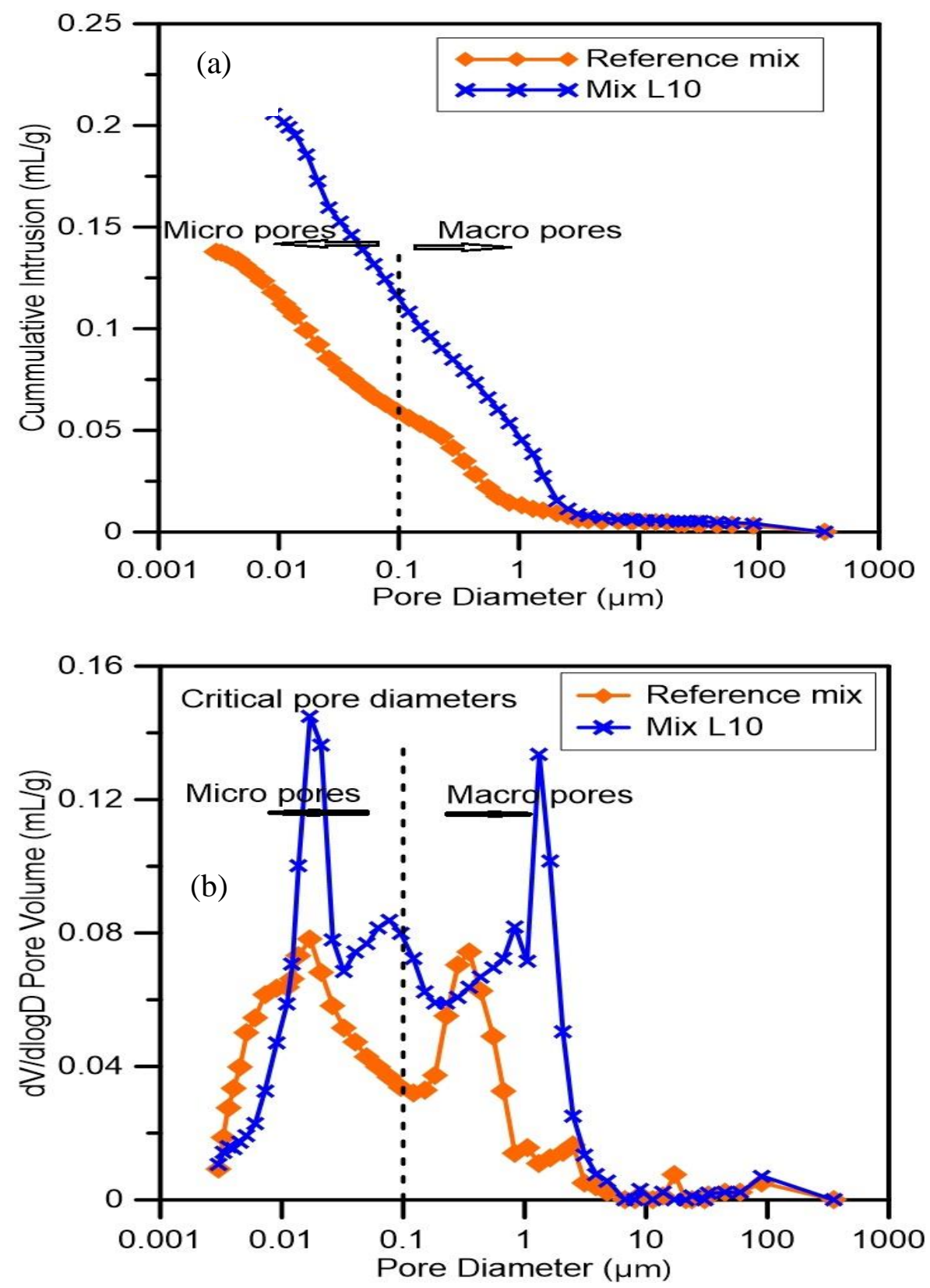

Figure 12. MIP results for the reference and L10 mix (a) mercury intrusion curves versus pore size diameter (b) derivative of MIP curves 
From the analysis, the reference concrete yielded a total intrusion volume and porosity of 0.1378 $\mathrm{mL} / \mathrm{g}$ and $26.04 \%$ respectively, and the L10 yielded a total intrusion volume and porosity of $0.2153 \mathrm{~mL} / \mathrm{g}$ and $35.29 \%$ respectively. Thus the reference mix was more compact and contains finer macro-pore systems than does the modified concrete, apparently due to a more rapid hydration of the matrix.

The MIP analysis clearly showed that the percentage of the pore volume in the ceramic-laterized specimen is greater than in the reference mix and fewer fine micropores and more macropores provide this void space (Figure 12b). As macro pores are more likely to form the initiating points for cracking under load, this helps to explain the weaker nature of mix L10 compared to the reference mix.

The high water content influenced coarse pore distribution in the ceramic-laterized mix, which was a result of slow hydration exhibited by the mixture. This sample also exhibited a high tortuosity (63.01), compared to 12.39 for the reference mix, as revealed in the MIP analysis software. The higher tortuosity in the laterized mixture was an indication that the concrete had a poor packing and heterogeneous orientation of grains, which created more convoluted pore channels.

\section{Conclusion}

This study has explored the microscale changes, mineralogy, porosity, phase change and strength properties of ceramic-laterized concrete, the following conclusions were drawn:

1. For all the concrete mixes considered in this study, both compressive and split tensile strengths increased as the curing days increased up to 91 days. The reference concrete has higher strength properties than the mixes containing alternative aggregates, this strength performance was attributed to a rapid hydration in the concretes and to lower void content and, in particular, lower macro pore volume which is expected to reduce crack initiation opportunities.

2. When fine aggregate is substituted by ceramic fine and laterite in the proportion $90 \%$ and $10 \%$ respectively, and ceramic coarse aggregate is used as coarse aggregate, both the compressive 
and split tensile strengths were higher than in other ceramic-rich mixes without laterite content, representing about $11 \%$ strength gain compared to the non-laterized ceramic concrete. Thus, although achieving the same strengths as a comparable conventional concrete is impossible when replacing these coarse and fine conventional aggregates with these ceramic aggregates, yet most of those strengths can be achieved through modest laterite addition.

3. The microstructural analysis of the selected samples indicated that the reference concrete has higher XRD peaks of Portlandite and Ettringite than does the laterized mix, which certainly was a result of adequate hydration in the concrete. The results of TGA and ITZ features also agree with the assertion. Based on the SEM micrographs obtained for the concrete samples, the reference mix showed a more compact microstructure, with a denser ITZ between the paste and the aggregates in the mix. However, there were some micro pores on the surface of the reference concrete, but this didn't impair the strength properties of the mixes.

4. Generally, those results obtained proved that the ceramic aggregate can be adequately used to supplement or totally replace natural aggregates in concrete, whilst laterite can be sparingly used as replacement for river sand. Consequently, when the materials are used as described in this study, it can create a sustainable alternative to the conventional concrete.

\section{Acknowledgements}

This research was funded by the Commonwealth Scholarship Commission in the United Kingdom, and the University of Nottingham (UoN), United Kingdom under grant number NGCN-2016-139. The technical staff of the concrete laboratory, UoN are appreciated for providing support during the mechanical assessment of concrete. The authors would like to thank Dr. Nigel Neate, Dr. Christopher Fox and Dr. Elisabeth Steer for assisting with the microscale analysis performed in this study.

\section{References}

[1] P. Lima, M. Leite, E. Santiago, Recycled lightweight concrete made from footwear industry waste and CDW, Waste Manag. 30 (2010) 1107-1113.

[2] S. Chung, C.W.H. Lo, Evaluating sustainability in waste management: the case of construction and demolition, chemical and clinical wastes in Hong Kong, Resour. 
Conserv. Recycl. 37 (2003) 119-145. doi:10.1016/S0921-3449(02)00075-7.

[3] C. Medina, M. Frías, M.I. Sánchez De Rojas, Microstructure and properties of recycled concretes using ceramic sanitary ware industry waste as coarse aggregate, Constr. Build. Mater. 31 (2012) 112-118. doi:10.1016/j.conbuildmat.2011.12.075.

[4] F. Andreola, L. Barbieri, I. Lancellotti, C. Leonelli, T. Manfredini, Recycling of industrial wastes in ceramic manufacturing: State of art and glass case studies, Ceram. Int. 42 (2016) 13333-13338.

[5] F. Pacheco-Torgal, Y. Ding, S. Miraldo, Z. Abdollahnejad, J. Labrincha, The suitability of concrete using recycled aggregates (RAs) for high- performance concrete (HPC), in: F. Pacheco-Torgal, V. Tam, J. Labrincha, Y. Ding, J. de Brito (Eds.), Handb. Recycl. Concr. Demolition Waste, Woodhead Publishing Limited, 2013: pp. 424-438. doi:10.1533/9780857096906.3.424.

[6] P.T. Jones, D. Geysen, Y. Tielemans, S. Van Passel, Y. Pontikes, B. Blanpain, M. Quaghebeur, N. Hoekstra, Enhanced Landfill Mining in view of multiple resource recovery: a critical review, J. Clean. Prod. 55 (2013) 45-55.

doi:10.1016/j.jclepro.2012.05.021.

[7] R. Senthamarai, P.D. Manoharan, D. Gobinath, Concrete made from ceramic industry waste: Durability properties, Constr. Build. Mater. 25 (2011) 2413-2419. doi:10.1016/j.conbuildmat.2010.11.049.

[8] J. de Brito, A.S. Pereira, J.R. Correia, Mechanical behaviour of non-structural concrete made with recycled ceramic aggregates, Cem. Concr. Compos. 27 (2005) 429-433. doi:10.1016/j.cemconcomp.2004.07.005.

[9] F. Pacheco-Torgal, S. Jalali, Reusing ceramic wastes in concrete, Constr. Build. Mater. 24 (2010) 832-838. doi:10.1016/j.conbuildmat.2009.10.023.

[10] F. Pacheco-Torgal, S. Jalali, Compressive strength and durability properties of ceramic wastes based concrete, Mater. Struct. 44 (2011) 155-167. doi:10.1617/s11527-010-96166.

[11] D.J. Anderson, S.T. Smith, F.T.K. Au, Mechanical properties of concrete utilising waste ceramic as coarse aggregate, Constr. Build. Mater. 117 (2016) 20-28. doi:10.1016/j.conbuildmat.2016.04.153.

[12] B.J. Olawuyi, K.O. Olusola, Compressive Strength of Volcanic Ash/Ordinary Portland Cement Laterized Concrete., Civ. Eng. Dimens. 12 (2010) 23-28. http://search.ebscohost.com/login.aspx ?direct=true\&profile=ehost\&scope=site\&authtype $=$ crawler\&jrnl=14109530\&AN=48666831\&h=2LQbCVqV4u2larY+k6NQpuc6gpVhZnPp 29yRUkSFg3mJJ+JVQu+4H04fY1 yC8cpNa2LEMqTW51bP6c/+17cm2A==\&crl=c.

[13] L.A. Balogun, D. Adepegba, Effect of Varying Sand Conctent in Laterized Concrete, Int. J. Cem. Compos. Light. Concr. 4 (1982) 235-240.

[14] F.F. Udoeyo, U.H. Iron, O.O. Odim, Strength performance of laterized concrete, Constr. Build. Mater. 20 (2006) 1057-1062. doi:10.1016/j.conbuildmat.2005.03.002.

[15] P.O. Awoyera, J.O. Akinmusuru, J.M. Ndambuki, Green concrete production with ceramic wastes and laterite, Constr. Build. Mater. 117 (2016) 29-36. doi:10.1016/j.conbuildmat.2016.04.108.

[16] X.S. Shi, F.G. Collins, X.L. Zhao, Q.Y. Wang, Mechanical properties and microstructure analysis of fly ash geopolymeric recycled concrete, J. Hazard. Mater. 237-238 (2012) 2029. doi:10.1016/j.jhazmat.2012.07.070.

[17] A. Fernandez-Jimenez, I. García-Lodeiro, A. Palomo, Durability of alkali-activated fly ash 
cementitious materials, J. Mater. Sci. 42 (2007) 3055-3065. doi:10.1007/s10853-0060584-8.

[18] J.M. Paris, J.G. Roessler, C.C. Ferraro, H.D. DeFord, T.G. Townsend, A review of waste products utilized as supplements to Portland cement in concrete, J. Clean. Prod. 121 (2016) 1-18. doi:10.1016/j.jclepro.2016.02.013.

[19] S. Puligilla, P. Mondal, Role of slag in microstructural development and hardening of fly ash-slag geopolymer, Cem. Concr. Res. 43 (2013) 70-80. doi:10.1016/j.cemconres.2012.10.004.

[20] C. Costa, Hydraulic Binders, in: M.C. Gonçalves, F. Margarido (Eds.), Mater. Constr. Civ. Eng. Sci. Process. Des., Springer International Publishing, Cham, 2015: pp. 1-52. doi:10.1007/978-3-319-08236-3_1.

[21] S. Wu, X. Chen, J. Zhou, Tensile strength of concrete under static and intermediate strain rates: Correlated results from different testing methods, Nucl. Eng. Des. 250 (2012) 173183. doi:10.1016/j.nucengdes.2012.05.004.

[22] S. Erdem, A.R. Dawson, N.H. Thom, Microstructure-linked strength properties and impact response of conventional and recycled concrete reinforced with steel and synthetic macro fibres, Constr. Build. Mater. 25 (2011) 4025-4036.

doi:10.1016/j.conbuildmat.2011.04.037.

[23] V. Vaitkevi?ius, E. ?erelis, H. Hilbig, The effect of glass powder on the microstructure of ultra high performance concrete, Constr. Build. Mater. 68 (2014) 102-109. doi:10.1016/j.conbuildmat.2014.05.101.

[24] BS 812-112, Testing aggregates. Method for determination of aggregate impact value (AIV), Br. Stand. London, UK. (1990).

[25] BS 812-110, Methods for determination of aggregate crushing value (ACV), Br. Stand. London, UK. (1990).

[26] part 1 NIS 444, Composition, specifications and conformity criteria for common cements, Niger. Ind. Stand. Center, Niger. (2003).

[27] BS 12:1989, Specification for ordinary and rapid-hardening Portland cement, Br. Stand. London, UK. (n.d.).

[28] BS 1377-2, Methods of test for soils for civil engineering purposes. Classification tests, Br. Stand. London, UK. (1990).

[29] P.O. Awoyera, A.R. Dawson, N.H. Thom, J.O. Akinmusuru, Suitability of mortars produced using laterite and ceramic wastes: Mechanical and microscale analysis, Constr. Build. Mater. 148 (2017) 195-203. doi:10.1016/j.conbuildmat.2017.05.031.

[30] ASTM C618, Standard Specification for Coal Fly Ash and Raw or Calcined Natural Pozzolan for Use in Concrete, Am. Soc. Test. Mater. (2008).

[31] 12390-3 BS EN, Testing hardened concrete - part 3: Compressive strength of test specimens, (2003).

[32] 12390-6 BS EN, Testing hardened concrete - part 6: Tensile splitting strength of test specimens, (2006).

[33] K.. Kjellsen, A. Mons?y, K. Isachsen, R.. Detwiler, Preparation of flat-polished specimens for SEM-backscattered electron imaging and X-ray microanalysis?importance of epoxy impregnation, Cem. Concr. Res. 33 (2003) 611-616. doi:10.1016/S0008-8846(02)010293.

[34] C.A. Oyelami, J.L. Van Rooy, A review of the use of lateritic soils in the construction/development of sustainable housing in Africa: A geological perspective, J. 
African Earth Sci. 119 (2016) 226-237. doi:10.1016/j.jafrearsci.2016.03.018.

[35] P.O. Awoyera, J.O. Akinmusuru, A. Moncea, Hydration mechanism and strength properties of recycled aggregate concrete made using ceramic blended cement, Cogent Eng. 4 (2017). doi:10.1080/23311916.2017.1282667.

[36] M. abd allah Abd elaty, Compressive strength prediction of Portland cement concrete with age using a new model, HBRC J. 10 (2014) 145-155. doi:10.1016/j.hbrcj.2013.09.005.

[37] M. Atan, H. Awang, The compressive and flexural strengths of self-compacting concrete using raw rice husk ash, J. Eng. Sci. Technol. 6 (2011) 720-732.

[38] M. Arezoumandi, J. Volz, J. Myers, Shear behaviour of high-volume fly ash concrete versus conventional concrete, J. Mater. Civ. Eng. 25 (2013) 1506-1513. doi:10.1061/(ASCE)MT.1943-5533.0000700.

[39] F. Liu, J. Liu, B. Ma, J. Huang, H. Li, Basic properties of concrete incorporating recycled ceramic aggregate and ultra-fine sand, J. Wuhan Univ. Technol. Sci. Ed. 30 (2015) 352360. doi:10.1007/s11595-015-1152-3.

[40] J.A. Rossignolo, Interfacial interactions in concretes with silica fume and SBR latex, Constr. Build. Mater. 23 (2009) 817-821. doi:10.1016/j.conbuildmat.2008.03.005.

[41] Y. Cheng, F. Huang, R. Liu, J. Hou, G. Li, Test research on effects of waste ceramic polishing powder on the permeability resistance of concrete, Mater. Struct. 49 (2016) 729-738. doi:10.1617/s11527-015-0533-6.

[42] M.K. Mohammed, A.R. Dawson, N.H. Thom, Production, microstructure and hydration of sustainable self-compacting concrete with different types of filler, Constr. Build. Mater. 49 (2013) 84-92. doi:10.1016/j.conbuildmat.2013.07.107.

[43] J.M. Gao, C.X. Qian, H.F. Liu, B. Wang, L. Li, ITZ microstructure of concrete containing GGBS, Cem. Concr. Res. 35 (2005) 1299-1304. doi:10.1016/j.cemconres.2004.06.042.

[44] A.J. Buttress, D.A. Jones, C. Dodds, G. Dimitrakis, C.J. Campbell, A. Dawson, S.W. Kingman, Understanding the scabbling of concrete using microwave energy, Cem. Concr. Res. 75 (2015) 75-90. doi:10.1016/j.cemconres.2015.04.009.

[45] H. El-Hassan, Y. Shao, Z. Ghouleh, Reaction Products in Carbonation-Cured Lightweight Concrete, J. Mater. Civ. Eng. 25 (2013). doi:10.1061/(ASCE)MT.1943-5533.0000638 10.1061/(ASCE)MT.1943-5533.0000638.

[46] P. Awoyera, Forensic Investigation of Fire-Affected Concrete Buildings, LAP LAMBERT Academic Publishing, 2014.

[47] P.H.R. Borges, J.O. Costa, N.B. Milestone, C.J. Lynsdale, R.E. Streatfield, Carbonation of $\mathrm{CH}$ and $\mathrm{C}-\mathrm{S}-\mathrm{H}$ in composite cement pastes containing high amounts of BFS, Cem. Concr. Res. 40 (2010) 284-292. doi:10.1016/j.cemconres.2009.10.020. 